\title{
The Creative Analytic Paradigm and Generative Social Research within the Context of the Early- Years/Kindergarten Physical Learning Environment
}

\author{
Anthony Barnett ${ }^{*}$ \\ Institute of Education, University of Worcester, Worcester, England \\ *Corresponding author: a.barnett@worc.ac.uk
}

Received April 25, 2014; Revised April 28, 2014; Accepted April 29, 2014

\begin{abstract}
Innovative approaches to research methodology are a potential counterbalance to the dominance of established methods and may be more responsive to specific research aims. However, approaching research differently incurs risks associated with evaluation of quality of methods and outcomes. This article starts the process of engaging with key methodological issues to provide a foundation for developing an innovative approach. The starting point is a focus on categorisation theory related to qualitative, quantitative and mixed methods. The article focuses on superordinate, basic and subordinate categories when responding to the stretching boundaries of qualitative research. Attention is then given to the concept of research paradigm; role of research questions; approaches to data collection and analysis; and to assessing quality as some of the starting points for developing an innovative approach. The creative analytic paradigm as a basic category and generative social research as a superordinate category are introduced and exemplified with reference to the early-years/kindergarten learning environment. The article then illustrates a subordinate category research design that involves the burgeoning of experience though time in response to evocative objects from the early-years learning environment. The resulting methodology is a straightforward and manageable form of meaning based reflective practice.
\end{abstract}

Keywords: innovative research methodology, paradigm, reflective practice

Cite This Article: Anthony Barnett, "The Creative Analytic Paradigm and Generative Social Research within the Context of the Early-Years/Kindergarten Physical Learning Environment.” American Journal of Educational Research, vol. 2, no. 5 (2014): 283-290. doi: 10.12691/education-2-5-8.

\section{Introduction}

Approaching research differently incurs the risk that the innovative methodology and substantive outcomes may be judged as lacking in quality, and innovation for its own sake is likely not to be a good reason for taking the risk. However, Dadds \& Hart [11] made the inspirational comment that,

'methodological innovation, far from transgressing the norm, ought perhaps to be accepted as a more natural, necessary and legitimate part of any open-minded research culture that is seeking to enhance quality' (p. 167).

What follows is an outline of an innovative way of thinking about and doing educational research that originated in the perceived need to give a greater sense of experienced reality to the object of the research as part of a discourse of meaning. The article begins by establishing a context through an introduction to categorisation theory and continues by focusing on concepts of research paradigm, research questions, data collection, analysis and quality. The encompassing context of generative social research is then considered before illustrating a particular research design aimed at raising insignificant details of experience to significance.

\section{Categorisation Theory}

Even a cursory review of literature in the area of categorisation theory $[12,19,30,33,39,48,50]$ is enough to recognise that this is a difficult and complex topic. The normative nature of quantitative and qualitative research was highlighted by Creswell [10] who emphasised that the utility of 'quantitative' and 'qualitative' as descriptors of research has tended to be rejected by mixed methods researchers 'in favour of a continuum for presenting qualitative and quantitative differences' (p. 273). Lakoff's [26] theory of idealised cognitive models provides a useful foundation for considering categorisation of educational research as motivated and normative rather than based in essentialist classical categorisation theory. The idea of category levels for research methodology was suggested by Lakoff [26] when referring to Rosch's example of 'animal' as superordinate, 'dog' as basic and 'retriever' as subordinate in relation to the study of basic-level prototype effects. In relation to research methodology the concepts would be recognisable as 'type of research', 'research paradigm' and 'research design'. The concept of research design would be identifiable as a subordinate category, research paradigms as basic categories and 
research type e.g. qualitative and quantitative as the encompassing superordinate category.

The approach to engaging with this task of outlining an innovative approach to educational research has been to explicate a particular research paradigm (basic category of research) referred to as the creative analytic paradigm (CAP) and to encompass this within a superordinate category of research referred to as generative social research (GSR). A particular illustration at the subordinate category level of research design focuses on the substantive area of the early-years (kindergarten/ Reception ages) physical learning environment.

\section{The Concept of Research Paradigm}

It will be useful to begin by focusing on the concept of paradigm. The concept of 'paradigm' was introduced into research discourse by Thomas Kuhn following publication of his Structure of Scientific Revolutions [25]. The approach to understanding the nature of science prior to this is exemplified by Empiricism originating in the philosophical perspective of John Locke (1632-1704) and the hypothetico-deductive falsificationist theory of Karl Popper (1902-1994). The Empiricist view located the source of all knowledge in sense perception and led to the modern concept of objectivity and use of the term positivism. Uniformity of scientific language and inductive generalisation led to the statement of scientific laws and truth claims proved by repetition of observations. This Empiricist view was undermined by developments in the theory of perception suggesting that viewpoints are perspectival and Karl Popper, engaging with the problem of induction, argued that it is not possible to prove the truth of a statement but only to know that it is false. When comparing the viewpoints of Popper and Kuhn, Masterman (1970) regarded Popper's concept of science as a form of 'aetherial philosophicness' contrasted with Kuhn's focus on the essential concreteness of science. Masterman (1970) noted 21 different uses of the word 'paradigm' in the 'Structure of Scientific Revolutions' and grouped these uses into three categories: metaphysical paradigm, sociological paradigm and construct paradigm.

In light of critiques by Masterman and others, Kuhn [25] published a postscript to 'The Structure of Scientific Revolutions' in which he acknowledged the confusion caused by the multiple meanings he had ascribed to the concept of paradigm. In the postscript Kuhn revised the concept and presented two fundamental meanings: one relating to community of practitioners and the other to use of exemplars. He explained that his original intention was to account for the common perception, judgment and unproblematic communication within identifiable professional communities, which therefore includes the metaphysical paradigm. With regard to this community of practitioners concept of paradigm Kuhn noted,

'...less confusion will result if I instead replace it with the phrase 'disciplinary matrix' - 'disciplinary' because it is the common possession of the practitioners of a professional discipline and 'matrix' because it is composed of ordered elements of various sorts, each requiring further specification. Constituents of the disciplinary matrix include most or all of the objects of group commitment described in the book as paradigms, parts of paradigms, or paradigmatic' (p. 297).

Kuhn's second revised fundamental sense of the use of 'paradigm' was as an exemplar which matches his construct paradigm use referred to by Masterman.

'Once a new problem is seen to be analogous to a problem previously solved, both an appropriate formalism and a new way of attaching its symbolic consequences to nature follow' [[25] p. 306].

Guba [17] recognised the difficulty of defining the term 'paradigm' by referring back to the multiple uses of the term by Thomas Kuhn. He valued the lack of clarity as this paved the way for developing understanding through consideration of conceptual issues. In a simple statement he referred to paradigm generically as 'a basic set of beliefs that guides actions' (p. 17) and then expressed the view, underpinned by Kuhn's concept, that all paradigms are characterised by ontological assumptions about the nature of reality, epistemological assumptions about the relationship between the knower and the known and methodological assumptions about the knowledge acquisition process.

'The answers that are given to these questions may be termed, as sets, the basic belief systems or paradigms that might be adopted' (p. 18).

Guba's [17] perspective reflects a separation of ontology from epistemology and the labelling of specific combinations. However, Hognestad \& Boe [20] developed a perspective based on a merging of ontology and epistemology referred to as 'onto-epistemological thinking'. Drawing on the Deleuzian concept of diffraction within the context of the kindergarten as a physical setting, Hognestad \& Boe [20] emphasised the view of Lenz Taguchi [29] that,

'A diffractive 'reading' is [thus] not a reading of a photograph as in taken-for-granted understanding, but a reading with the photograph in your encounter with it. In this event something new is created with the data' (p. 537)

The creative analytic paradigm (CAP) is also a form of 'onto-epistemological thinking' that merges knowing and being. As a reflective process, the CAP is more of a passive serendipitous background activity rather than an exhaustive systematic collection of data and active interrogation and extraction of meaning. As with human relationships space for the relationship to develop and valuing of the other are signs of a flourishing and worthwhile relationship whereas interrogation can be a sign of the impending breakdown of the relationship. Uncertainty can be the spark that adds value. Hognestad \& Boe [20] noted that they 'experienced how a relational ontology focussing on relations in something rather than relations to something can be useful in methodology' ( $p$. 53). In the CAP the corresponding concept of 'being-inrelation-to' the object of the research emphasises the existential state of being that develops through time. Analysis is not so much a detached deconstructive process as an involvement and openness to experience. Shon's [42] idea of developing a reflective conversation with the situation and Baker et al's [2] idea of conversational learning have an affinity with this concept of process as relationship, as also does Martin Buber's I-Thou/ I-You/ IIt philosophy. 
'I can look on (a tree) as a picture: stiff column in a shock of light, or splash of green shot with the delicate blue and silver of the background.

I can perceive it as movement: flowing veins on clinging, pressing pith, suck of the roots, breathing of the leaves, ceaseless commerce with earth and air - and the obscure growth itself.

I can classify it in a species and study it as a type in its structure and mode of life.

I can subdue its actual presence and form so sternly that I recognize it only as an expression of law...

I can dissipate it and perpetuate it in number...

In all this the tree remains my object, occupies space and time, and has its nature and constitution.

It can, however, also come about, if I have both will and grace, that in considering the tree I become bound up in relation to it. The tree is no longer It. I have been seized by the power of exclusiveness.

Martin Buber (1958) I and Thou, pages 19-20’ [43].

\section{The Concept of Research Question}

Research typically involves use of research questions in order to provide permeable boundaries [24] or as navigational tools for providing shape and direction as part of an on-going reflective process at all stages of a qualitative study [1]. Sometimes these broader research questions are stated as goals or expressions of purpose rather than as questions. However, the link between research questions and methods is complicated by a range of factors and Bryman [7] suggested that the prevailing view, 'functions as an occupational ideology that contributes to conveying a sense of the rationality and rigour of its members' craft' (p. 18). The questioning of the role of the research question was reinforced by KoroLjungberg \& Hayes [24] who noted that not all researchers would agree that research questions have a central role within the research design, and by Bryman [7] and Agee [1] who noted that research questions do not always mark the start of a research study.

The CAP is based in and motivated by the concept of evocative objects that was introduced by Turkle [46]. Sherry Turkle's [46] 'Evocative Objects: Things We Think With' is an edited collection of brief reflections by a range of contributors including psychologists, philosophers, designers, architects and musicians. Each of the reflections is based on an everyday object, regarded 'as a companion in life experience' (p. 5), chosen by each contributor as having some emotional and intellectual significance, as an evocative object e.g. a cello, ballet slippers, a bracelet, a silver pin, a suitcase and apples.

Harman [51] refers to Turkle's 'evocative objects' as having characteristics of autonomy, richness and depth, which relates to their identity and 'swarming inner infinites' (p. 456).

'Surely even the dullest of objects are laced with songs and legends that await their bards’ (455).

\section{The Approach to Data Collection and Analysis}

The approach to analysis in relation to the evocative objects model involves developing a state of being-in- relation-to the object that is both generative and divergent. This is a process model which uses the evocative object as a source of ideas generation through repeated revisiting of the object over a period of time. The emphasis is on the process through time of generating a range of speculative meanings and elaborative interpretation of the evocative objects. Meanings emerge as part of the developing relationship with and valuing of the object, not by a systematic and detached process of analysis.

Generative divergent analysis (GDA) is an imaginative additive process of generating alternative speculative reflections and the analytical process is essentially a creative burgeoning of experience through time. The fluency, flexibility and originality of thinking referred to by Guilford, elaborative interpretation referred to by Novitz [38] and the use of orienting concepts to kick start the thinking process as referred to by Layder [28] are some of the possible starting points for engaging with experience in this creative way. This more creative approach to analysis recalls the creation of nomadic pathways and transcendental empiricism of Deleuze \& Guitari [13].

The specific character of generative divergent analysis is marked by a 'turning towards' and 'turning away' from the evocative object as part of a developing being-inrelation-to relationship with the object. The collections of speculative reflections and elaborating interpretations of evocative objects constitute satellite topics [3] conceived of as unfinished resources for thinking [5]. Although Hognestad \& Boe [20] noted that they 'experienced how a relational ontology focussing on relations in something rather than relations to something can be useful in methodology' (p. 53), the 'being-in-relation-to' component of the generative divergent analysis model nonetheless also involves a decentring of the agency of the researcher as suggested by the valuing of the relationship with the object.

\section{Considering Quality}

The literature in the area of evaluating quality is extensive and covers a diverse range of views on a range of issues. For example, there are those who have rejected evaluation criteria altogether (Smith 1984); and relativist viewpoints such as Schwandt's 'Farewell to Criteriology' [41]. Other views express the need for paradigm specific criteria and criteria related to specific research traditions e.g. Waterman's [49] view that 'qualitative perspectives on validity do not portray adequately all that which makes action research valid' (p. 101) and that action research should be evaluated in terms of dialectic, critical and reflexive validity. Noteworthy in this context is Spencer et al's [44] identification of 39 adjectives appended to the word validity during their review of the literature including pragmatic, predictive, catalytic and construct validity to mention just a small sample; and still yet other views support the adoption of a set of universally applicable criteria [45]. Emden \& Sandelowski [16] recorded a detailed history of the response of qualitative researchers to the concepts of validity and reliability, categorising the range of alternative quality criteria in terms of the traditional concepts 'being championed, translated, exiled, redeemed, and surpassed' (2). 
Where research paradigms have common elements it may be appropriate to use common quality criteria. However, evaluation of the quality of research ought to also consider the unique character of the approach as suggested, for example, by McNiff, Whitehead \& Lomax [32] in relation to the distinctive features of educational action research. From the point of view of who should determine evaluation criteria, researchers responsible for producing the research design and carrying out the research, who are directly engaged with doing the research, are likely to be in a very good position to identify custom quality criteria and this is particularly relevant in relation to an innovative approach to research.

The creative analytic paradigm (CAP) is primarily concerned with generating meanings and with personally meaningful experience. The particular character of the CAP is the surface impressions and layers of meaning that differentiate the perceptual and conceptual field. Whereas some forms of research may attempt to produce a cognitive map of reality or to faithfully represent views of participants, the CAP aims to develop associations with evocative objects encountered in the empirical domain. It is essentially a personal encounter and relationship concept where the quality of experience is personally valued. Also, insofar as the CAP is an ongoing process the judgment of quality is itself subject to continuous revision. The CAP adopts a value position as a form of nonsystematic inquiry and as with semiotics its approach could be considered impressionistic and subjective. However, the 'individual readings' referred to by Chandler [9] and overlaid meanings are more appropriately referred to as exemplified possibilities, speculative ideas and elaborative interpretation. As such, partially formed ideas can have as much or more value than specific or precisely formulated ideas. Quality can exist just as much in ambiguity as in well-formed explanations. Driven by the motivation of contemplative reflection rather than by the urgency of a specific research question, quality can also arise through the pervasiveness of the generated meanings in consciousness.

\section{The Encompassing Context of Generative Social Research}

Questions of quality draw attention to the need to consider the broader context. Lakoff's [26] concept of idealised cognitive models (ICM) includes a range of different types of ICM. The 'cluster' and 'radial' models provide an initial way of visualising the superordinate category of generative social research. The concept of 'mother' helps by drawing attention to Wittgenstein's [50] family resemblances way of thinking that is particularly evident in these models. Essentially the birth mother has little if any logically necessary connections to the nurturing mother, the surrogate mother, the genetic mother, the foster mother and the unmarried mother. However the concept of mother itself is a cluster of these different meanings.

'A radial structure is one where there is a central case and conventionalized variations on it which cannot be predicted by general rules' [26].

Various research paradigms suggest themselves as potential candidates comprising a generative social research category, with varying degrees of typicality related to the CAP as one prototypical form: exploratory research [52] - seen as least typical because of being a preliminary stage in a larger process; forms of critical pedagogy which include evidence of possibility thinking (Brown \& Jones 2001) - potentially typical though bounded by the focus on equity and social justice issues; forms of arts based research $([36,40])$ - which may gain in typicality through Eisner's [14] claim that 'Our propensity to change practice is a function of the attractiveness of a set of ideas, rather than the rigour of a body of data-based conclusions' (p. 89) and; approaches involving semiotics such as that of Junge [23] - particularly forms taking a more constructivist approach.

The rationale for considering generative social research as a separate superordinate category contrasted with quantitative, qualitative and mixed methods approaches relates particularly to the evaluation of the quality of social research at the boundaries. Wittgenstein [50] drew attention to category formation through family resemblances and the extension or stretching of the boundaries of qualitative research may also contribute to an erosion of a conceptual core and pave the way for an alternative categorisation. This would allow a recentering of the locus of evaluation of potentially marginalised forms of research. A superordinate category, such as the idea of generative social research, identified through cluster of examples including the CAP, exploratory research, critical pedagogy, arts-based research and semiotics suggests a range of possible variations. For example, the collaborative fabrication of evidence undertaken by the participants in Rasberry's research is very different from the more persuasive individual reading that is typical of semiotic approaches. Another example is the ideas generated within types of exploratory research which may take the form of suggestions and questions rather than interpretations. The status and form of generated perspectives may also differ from being a preliminary and instrumental stage, part of an approach to conversational learning [2] or an aspect of continuing professional development, through to being an integrated end point and part of a personal aesthetic as in the CAP.

\section{Exemplification of the creative analytic paradigm}

\subsection{Satellite topic}

One particular application of the creative analytic paradigm focuses on raising insignificant details of experience to significance. Whereas Bruster \& Peterson [6] drew attention to 'critical incidents' and Gunter [18] emphasised the 'big ideas' in research, intensified experiential reality can be cultivated through developing a reflective relationship that includes minor details, passing impressions, memorable moments and 'bafflements' [5]. The significance of one such insignificant detail, a pictorial timetable displayed within the reading area in a reception class, begins to take form through a contemplative awareness expressed as a simple poem (Figure 1). The poem itself arose spontaneously from images around the class and following conversation with a student teacher in the class at the time, who was initially 
unaware of the existence of the pictorial timetable. Initial associated ideas are evident in 'unnoticed', 'entangled', 'redundant', 'parental involvement'.

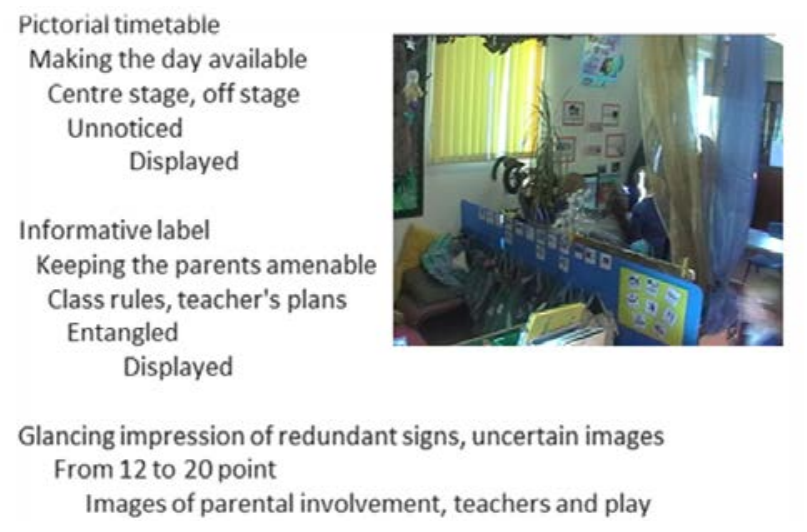

Figure 1.

Mac Naughton [37] noted that performing with language is a process of constructing rather than representing reality, '...through creating social conventions about what meanings should link with certain signs' (88). Laclau \& Moufe [21]) extend the focus to include engagement with objects, emphasising that whenever objects exist they have meaning as part of discourse The Foucaultian parallel, views discourse 'as practices that systematically form the objects of which they speak' [8] p. 38. These views relate well to the additive process of overlaying meanings through generative divergent analysis (GDA).

As a first stage 'turning towards' the evocative object suggests that a primary meaning is that children leave their book bags in the reading area and incidentally get reminded of how the day is structured. Turning towards the object may also suggest other meanings as part of a direct focus on the pictorial timetable: support for learning; helps to inform the parents; conveys particular meanings related to its design features and; represents the distributed authority of the teacher.

Consistent with the non-systematic approach of the GDA model, although 'organising the day' was the chronologically initial 'turning towards' meaning, the evocative object is revisited as part of the more flexible and opportunistic way of becoming acquainted with the object. For example, although the topic was commenced in 2009/10, revisiting 'organising the day' during 2012 occurred as part of a further imaginative elaboration of the object using the orienting concepts of distributed cognition and actor network theory. This suggested that the timeline could be regarded as one of the non-human actants within an actor network understood as a classroom management system (other non-human actants would be the range of other prompts and reminders included throughout the setting). This process may gain support from further experiential encounters with the object or similar objects. Direct experience of several early-years settings in this period provided evidence of a variety of practices in relation to the use of pictorial timetables: they are not visible at all in some settings, in others they are located off stage as here or are not in active use, and in yet others they are located by the teacher's chair where the children sit at the start of the day. Time of year may also be important as suggested in the following conversation with a nursery class teacher at the beginning of the school year, which emphasises that some children may be 'nervous or upset about leaving home...' (Nursery class teacher)

Me: When they start the day whereabouts do they start and do they come and sit on the carpet?

T1: Yeah, they start the day by getting their photographs and registering themselves and place their photo on the number. Then they know to come and sit down with their parents, choose a book... and we have about quarter of an hour of parents dropping in time... reading, sharing books. It gives the parents the opportunity to have a chat as well if they want to.

Me: Okay, let's just move round the classroom... so these are the displays...

T1: (Hurriedly calling me back, suggesting I'd missed something important) Do you want to talk about the timetable as well?

Me: Yes please..

T1: ... because that's the next thing. After we've counted up how many children are here we go onto the timetable. I find that really helpful because the children like routine, they like to know what's happening next and also the ones that are nervous or upset about leaving home know that home comes at the end...

INT: Oh I see.

T1: ... yeah, so It's very useful... I mean I bought it in for a child that had Aspergers but actually realised it's useful for all the children; they really get on well with it.

(Nursery class teacher)

Awareness of different practices in relation to 'pictorial timelines' provides a sense of direction for the 'turning away' component of the GDA model. Although 'turning away' is not constrained by any predetermined parameters, the encompassing broader category of different pedagogical approaches [34] begins to suggest that insignificant details of experience can be located as part of a larger theoretical perspective:

Displayed timeline: 'Reggio Emilia' approach Classroom as the third teacher (and alternatively the concept of the hidden curriculum begins to emerge)

No timeline: e.g. 'Montessori' approach - Natural biorhythms of the child (this does not suggest that all schools where there is no pictorial timetable are following a Montessori approach).

Active timeline: e.g. High Scope approach - active 'plan, do review':

Deconstructing the idea of the classroom as the third teacher enables potential meanings conveyed by the pictorial timeline to be considered further:

As a semiotic resource the timeline can be interpreted as a 'support for learning'. The broader concept of reading includes images and visual literacy rather than just text. The pictorial timetable (arranged in the usual left to right order for reading) can be understood, within its reading area location, as providing children with a broader concept of reading. Other relevant constituents serving the same purpose within the reading area would be posters and even a non-linear text on the computer. Also the nature of the images themselves may communicate different meanings e.g. a stick figure holding a book as representative of 'reading time' may be perceived differently to a photo picture of a boy and a girl showing clear signs of interest when reading a shared book while sitting on comfortable 
cushions. The study of semiotics (Chandler 2002) suggests that both the design and location of the timeline, as well as its absence, may contribute to the signification of the learning environment. Relocating the pictorial timeline to the maths area could change its more active signification: instead of being a means for broadening the concept of reading the timeline would support developing ability to tell the time, sequencing and ordering.

The discourse theory of Laclau \& Mouffe [21] focused on concepts of antagonism and hegemony. Such concepts can also generate meanings in relation to the pictorial timetable which is available to the parents who may sit with their children in the reading area at the start of the day for 10-15 minutes. The following transcript from an interview with a student teacher on placement in a Reception class illustrates the place of parents and child minders within the setting:

Me. (Referring to printed information cards displayed in the numeracy area) Are these meant for the children...?

S. ... it's all about having literacy within the environment, so even though they can't read it it's still there... it conveys meaning... it's important to have it there anyway. But it's also for the parents so that when they drop their children off in the morning they know what they're doing and can see the kind of targets we are getting the children to do...

Me. Do you get a lot of parents in here?

$S$. Yes they all come in with their children. It's sort of a Stay and Play for about 10 - 15 minutes...

Me. These things (posters on the wall by the door) like Early Learning Goals ... and Our Literacy, they are obviously for the adults... I know you mentioned about having 'words around you' but...

$S$. That's actually for, ... it's a scheme we are trying to set up where ... we have a lot of child minders and parents: if they see the children doing something significant at ... they can find it and put a sticker on or Post-it on so that it links to ... (from interview with PGCE student during school placement)

As highlighted by Moriarty [35] signs, relating to how the school functions, communicate to parents how they might support the school and its aims; the focus of Jones, Holmes \& Powell [22] on the nature of 'parental involvement' draws attention to the complexity of this concept. This discourse may locate parents as clients and consumers rather than as co participants in early-years settings which support and learn from the values of the parents e.g. as for early-years practice in Finland. An element of potential antagonism is also not far removed from the interaction between schools, school systems and parents. In this regard, Ejieh [15] noted a conflict of interest between parents and schools in Nigerian Early Years practice, where parents wanted the language of instruction to be English but the official policy was for use of the mother tongue.

Cannella [8] took up the theme of childhood as a social construction from a Foucaultian perspective and sought to problematise early-years education using the concept of disciplinary technologies, 'described as objectifying practices in a culture that would produce 'docile bodies" (p. 40). This seems particularly relevant to the current preoccupation with the pictorial timetable. The glancing impression is that the timetable was located within the reading area rather than at the front of the class by the teacher's chair. The positioning of this pictorial timeline is therefore an important constituent of its meaning. Off centre stage, (re the poem) in the reading area away from the teacher's area suggests a discourse of distributed authority and independence/interdependence. The disciplinary technologies referred to by Cannella include 'Teaching and Management Methods': the embeddedness of the timetable as part of the fabric of the setting (the ground rather than the figure) is suggestive of the Foucaultian notion of insidious disciplinary practices. This view is developed further by Batycky (2008) who referred to the 'linear, scientific mode of the curriculum as an oppressive structure' (p. 175). In relation to studentcentred classrooms, Scheurich \& Mckenzie [47] also expressed the Foucaultian view as a 'practice of power that is, in many ways, actually more oppressive than teacher-centred classrooms... because the work of this new tactic of power is to imprint the souls of the children rather than just their behaviours' (p. 855).

This satellite topic is a typical example of the way in which the GDA model encompasses engagement with the original evocative object through overlaying meanings in conjunction with orienting concepts. Throughout the topic the poetic encounter continues to resurface though the emergent themes move away from the object to engage with different pedagogic and theoretical perspectives, particularly classroom as third teacher, and include related images from other settings.

\subsection{Conceptual Canvas}

The combinational and transformational forms of creativity referred to by Boden [4], which suggest generation and combination of multiple viewpoints unbounded by mainstream educational discourse, and the concept of rhizome developed by Deleuze \& Guitari [13]. relate well to the idea of a conceptual canvas with a rhizomatic form as an outcome of the CAP. In relation to the CAP the idea of 'interconnection' is visible where similar meanings are overlaid on different evocative objects; and 'multiplicity' of meanings is evident within the context of the imaginative elaboration of evocative objects e.g. the pictorial timetable as a non-human actant within a classroom management system as well as a learning aid broadening the concept of reading and other meanings within a classroom as third teacher context. In terms of 'assemblage', increasing the number of evocative objects and satellite topics would increase the number of possible combinations as part of an active mapping of speculative ideas within an encompassing generic interpretation [27].

Mac Naughton [37] drew attention to the character and strategies of rhizoanalysis as a way of creating meaning by deconstructing and reconstructing texts. She gave particular emphasis to choosing and overlaying counter hegemonic texts as a way of questioning the dominant discourse. Mac Naughton associated rhizoanalysis specifically with issues of social equity and noted,

'The choices you make about what texts to layer into the meanings of your observations will link the rhizome you aim to build - to your political intent. The aim of rhizomatic logic is to link meanings (semiotic chains), such as gender meanings, with how power is organised and efforts to struggle for equity and justice' (p. 133). 
The scope of the CAP however is potentially broader insofar as the brief observations and glancing impressions are evocative objects unconstrained by any predetermined pathway. Figure 2 is a visual representation of how a conceptual canvas might evolve with a rhizomatic form. The circles and strands represent satellite topics originating in evocative objects (more developed satellite topics have larger circles and/or more strands (associated ideas) which suggests that some topics, although well developed, may have fewer interconnections than other topics).

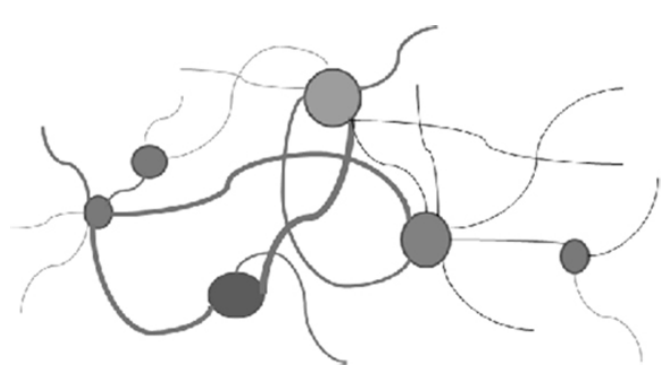

Figure 2.

The overlapping of meanings rapidly results in a complicated entanglement of burgeoning evocative objects (Figure 3). If the first satellite topic is called 'pictorial timetable', a second satellite topic emerges from a focus on a 'partition screen' and a third relates to a 'classroom display' and so on, then common meanings may begin with e.g. 'supporting learning' and 'independent learning'.

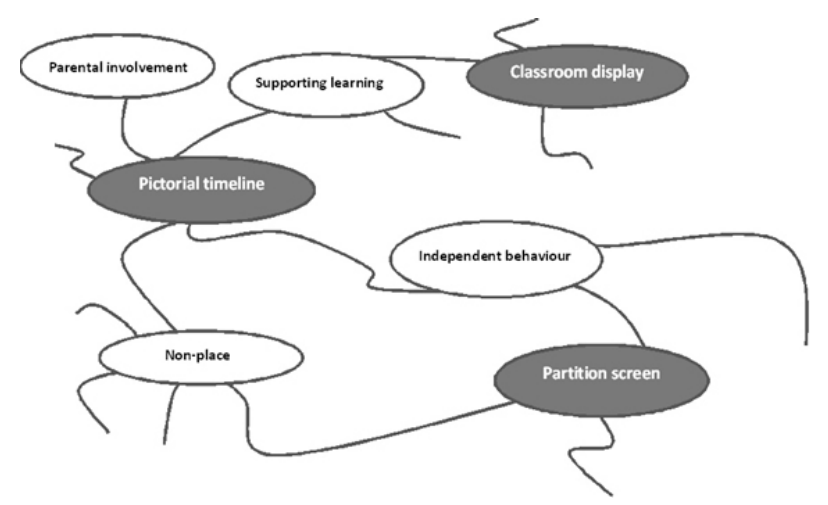

Figure 3.

As an innovative methodology, the emphasis in the creation of the conceptual canvas is on the ongoing beingin-relation-to the emerging evocative objects and developing satellite topics as part of a developing contemplative disposition.

\section{Acknowledgement}

(NB. This article based on my PhD thesis: Barnett 2013. It also relates to my paper presented at the BERA Annual Conference July 2013. Contact details: a.barnett@worc.ac.uk).

\section{References}

[1] Agee, J. (2009) Developing qualitative research questions: a reflective process International Journal of Qualitative Studies in
Education [Online] 22, 4, 431-447. Available from: http://www.tandfonline.com/doi/pdf/10.1080/09518390902736512

[2] Baker, A. C., Jensen, P. \& Kolb, D. (2002) Conversational learning: An experiential approach to knowledge creation [Online] Available from: http://learningfromexperience.com/researchlibrary/conversation-as-experiential-learning/

[3] Barnett, A 2013 Developing a creative analytic paradigm in relation to the early-years physical learning environment, Unpublished $\mathrm{PhD}$ thesis. University of Worcester.

[4] Boden, M. (2005) Creativity. In Gaut, B. \& Lopes, D. M. (Eds.) The Routledge Companion to Aesthetics, London, Routledge. pp. 477-488.

[5] Brown, T. \& Jones, L. (2001) Action Research and Postmodernism, Buckingham, Open University Press.

[6] Bruster, B.G., \& Peterson, B. R., (2013) Using critical incidents in teaching to promote reflective practice, Reflective Practice, 14 (2) 170-182.

[7] Bryman, A. (2007) The Research Question in Social Research: What is its Role? Int. J. Social Research Methodology [Online] 10, 1, pp. 5-20.

[8] Cannella, G. S. (1999) The Scientific Discourse of Education: predetermining the lives of others - Foucault, education, and children, Contemporary Issues in Early Childhood [Online] 1, 1, 36-44. Available from: http://www.wwwords.co.uk/rss/abstract.asp?j=ciec\&aid=1502

[9] Chandler, D. (2002) Semiotics: the basics, London, Routledge

[10] Cresswell, T. (2004) Place: a short introduction, Malden, MA, Blackwell.

[11] Dadds, M \& Hart, S(2001) Doing practitioner research differently, London, Routledge.

[12] Dey, I. (1999) Grounding Grounded Theory: Guidelines for Qualitative Inquiry, London, Academic Press.

[13] Deleuze, G. \& Guattari, F. (2004) Deleuze \& Guattari: A Thousand Plateaus, London, Continuum.

[14] Eisner, E. (2005) Reimagining Schools: the selected works of Elliot Eisner, London, Routledge.

[15] Ejieh, M. U. C. (2006) Pre-Primary Educataion in Nigeria: Policy Implementation and Problems Elementary Education Online [Online] 5, 1, 58-64. Available from: http://ilkogretimonline.org.tr/vol5say1/v5s1m6.PDF

[16] Emden, C. \& Sandelowski, M. (1998) The good, the bad and the relative, part one: Conceptions of goodness in qualitative research International Journal of Nursing Practice [Online] 4, 206-212. Available from: Academic Search Complete.

[17] Guba, E. (1990) The Alternative Paradigm Dialogue. In Guba, E. (Ed.) The Paradigm Dialogue. London, Sage.

[18] Gunter, H (2013) Thinking about research, Keynote lecture, BERA Annual Conference, $3-5^{\text {th }}$ Sept, University of Sussex.

[19] Harnad, S. (1987) Category induction and representation. In Harnad, S. (Ed.) Categorical perception: the groundwork of cognition. Cambridge, Cambridge University Press.

[20] Hognestad, K \& Boe, M (2012) 'Place' as conceptual centre: a methodological focus on the bodily relations, movements and expressions of children up to three years of age in kindergarten, Reconceptualizing Educational Research Methodology, 3 (2) 4355.

[21] Howarth, D. (2000) Discourse, Buckingham, Open University Press.

[22] Jones, L., Holmes, R \& Powell, J (2005) Early childhood studies a multiprofessional perspective, Maidenhead, Open University Press.

[23] Junge, M. (1994) The perception of doors: A sociodynamic investigation of doors in 20th century painting, The Arts in Psychotherapy, 21, 343-357.

[24] Koro-Ljungberg, M. \& Hayes, S. (2010) Proposing an argument for research questions that could create permeable boundaries within qualitative research Journal of Ethnographic \& Qualitative Research [Online] 4, 3, p. 114-124.

[25] Kuhn, T. (1996) The Structure of Scientific Revoltions, Chicago, University of Chicago Press.

[26] Lakoff, G. (1987) Women, fire and dangerous things: what categories teach us about the human mind, Chicago, Chicago University Press.

[27] Lamarque, P. (2000) Objects of interpretation. In Margolis, J. \& Rockmore, T. (Eds.) The Philosophy of Interpretation, Oxford, Blackwell. pp. 96-125. 
[28] Layder, D. (1998) Sociological Practice: linking theory and social research, London, Sage.

[29] Lenz Taguchi, H (2010) Doing collaborative deconstruction as an 'exorbitant' strategy in qualitative research, Reconceptualizing Educational Research Methodology, 1 (1), 41-53.

[30] Maclaury, R. (1991) Prototypes Revisited Annual review of anthropology [Online] 20, 1, 55-74. Available from: Academic Search Complete.

[31] Masterman, M. (1970) The Nature of a Paradigm. In Lakatos, I. \& Musgrave, A. (Eds.) Criticism and the Growth of Knowledge. London, Cambridge University Press.

[32] McNiff, J., Whitehead, J \& Lomax, P (2003) You and Your Action Research Project, London, Routledge Falmer.

[33] Medin, D. L. \& Barsalou, L. W. (1987) Categorisation processes and categorical perception. In Harnad, S. (Ed.) Categorial perception: the groundwork of cognition. Cambridge, Cambridge University Press

[34] Miller, L. \& Pound, L. (Eds.) (2011) Theories and Approaches to Learning in the Early Years, London, Sage.

[35] Moriarty, V. (1999) Early years proessionals and parents: challenging the dominant discourse? [Online] Available from: http://herkules.oulu.fi/isbn9514268539/html/t2659.html

[36] Mullen, C. \& Diamond, P. (2002) Showcasing Arts-Based Inquiries. In Bagley, C. \& Cancienne, B. (Eds.) Dancing the Data, New York, Peter Lang.

[37] Mac Naughton, G. M. (Ed.) (2005) Doing Foucault in Early Childhood Studies: applying postructural ideas, London, Routledge.

[38] Novitz, D. (2000) Interpretation and Justification. In Margolis, J. \& Rockmore, T. (Eds.) The Philosophy of Interpretation, Oxford, Blackwell. pp. 4-24.

[39] Poitrenaud, S., Richard, J.-F. \& Tijus, C. (2005) Properties, categories, and categorisation Thinking \& Reasoning [Online] 151-208. Available from: Academic Search Complete.

[40] Rasberry, G. W. (2002) Imagine, Inventing a Data-Dancer. In Bagley, C. \& Cancienne, B. (Eds.) Dancing the Data, New York, Peter Lang.
[41] Schwandt, T. (1996) Farewell to Criteriology. Qualitative Inquiry, 2, 58-74.

[42] Shon's (1991) Schon, D. (1991) The Reflective Practitioner - how professionals think in action, Aldershot, Ashgate.

[43] Smith, M. K. (2009) Martin Buber on education [Online] Available from: http://www.infed.org/thinkers/et-buber.htm

[44] Spencer, L., Ritchie, J., Lewis, J. \& Dillon, L. (2003) Quality in Qualitative Evaluation: A framework for assessing research evidence [Online] Available from: http://www.uea.ac.uk/edu/phdhkedu/acadpapers/qualityframework .pdf

[45] Tracy, S. J. (2010) Qualitative Quality: Eight "Big-Tent" Criteria for Excellent "Qualitative Research Qualitative Inquiry [Online] 16, 10, 837-842. Available from: http://qix.sagepub.com/content/16/10/837

[46] Turkle, S. (2007) Evocative Objects, London, The MIT Press.

[47] Scheurich, J. \& Mckenzie, K. (2005) Foucault's Methodologies: Archealogy and Genealogy. In Denzin, N. L., Y (Ed.) The Sage Handbook of Qualitative Research 3rd ed. London, Sage. pp. 841869.

[48] Vervaeke, J. \& Green, C. (1997) Women, Fire, and Dangerous Theories: A Critique of Lakoff's Theory of Categorization Metaphor and Symbol [Online] 12, 1, 59-80. Available from: Academic Search Complete.

[49] Waterman, H. (1998) Embracing ambiguities and valuing ourselves: issues of validity in action research Journal of Advanced Nursing [Online] 28, 1, 101-105. Available from: Academic Search Complete.

[50] Wittgenstein, L. (1967) Philosophical Investigations, Oxford, Blackwell.

[51] Harman, G. (2008) Zeroing in on Evocative Objects. Human Studies, 31, 443-457.

[52] Stebbins, R. (2001) Exploratory Research in the Social Sciences, London, Sage. 